LOCKE'S VS. TYRODE'S FOR PERFUSION OF SEGMENTS OF INTESTINE.

ROSS O. B. THORNTON AND HARRY L. LEAVITT. 


\section{Locke's vs. Tyrode's For Perfusion of Segments of Intestine.}

ROSS C. B. THORNTON AND HARRY L. IEAAVITT.

(Introduced by G. E. Burget.)

From the Department of Physiology, Wniversity of Oregon Medical School.

In previous work Tyrode's solution seemed to be inferior to Locke's for the perfusion of intestinal segments. MacLeod ${ }^{1}$ states: "Although undoubtedly superior for some perfused preparations. such as the intestine, it does not seem to be in any way superior to Locke's for the perfusion of the heart." It seemed desirable to investigate further the value of these solutions for intestinal perfusion under the ordinary laboratory procedure.

Segments of the small intestine of the rabbit and cat were used. The segments were taken well below the duodenum because the jejunum and ileum are less erratic in activity.

The solutions used were: Locke's ${ }^{2} \mathrm{NaCl}, 0.90 \%$; $\mathrm{KCl}$, $0.042 \% ; \mathrm{NaHCO}_{3}, 0.032 \% ; \mathrm{CaCl}_{2} \cdot 2 \mathrm{H}_{2} \mathrm{O}, 0.024 \%$; dextrose, $0.1 \%$. Tyrode's ${ }^{3} \mathrm{NaCl}, 0.80 \% ; \mathrm{KCl}, 0.02 \% ; \mathrm{NaHCO}_{3}, 0.10 \%$; $\mathrm{CaCl}_{2} \cdot 2 \mathrm{H}_{2} \mathrm{O}, 0.02 \% ; \mathrm{MgCl}_{2}, 0.01 \% ; \mathrm{NaH}_{2} \mathrm{PO}_{4}, 0.005 \%$; dextrose, $0.1 \%$. The salts were accurately weighed and the solutions freshly prepared. The same stock of C. P. chemicals was used throughout. The Magnus type of apparatus was used, the volume of which was $200 \mathrm{cc}$.

The animal was stunned, bled from the carotid artery, and the abdomen opened at once. A segment was taken well below the duodenum and from this the required number of smaller segments were cut and dropped into their respective solutions. As short a period

${ }_{1}$ MacLeod, J. J. R., "Physiology and Biochemistry in Modern Medicine," 5th edition, C. V. Mosby Co., 383.

2 Locke, F. S., and Rosenheim, O., J. Physiol., 1907, xxxvi, 205.

3 Tyrode, M. V., Arch. Intern. de Pharm. et de Therap., 1910, xx, 205. 
of time as possible was allowed to elapse from the moment the animal was stunned until the individual segment was attached to its respective piece of apparatus.

The $\mathrm{pH}$ of the solutions was obtained by the quinhydrone electrode. When a change of $\mathrm{pH}$ was desired a bath of warmed fresh solution was substituted for the bath already in use. When adrenalin was used, 1 or 2 drops of 1 to 10,000 solution prepared from Adrenalin, 1 to 1,000 , Parke Davis, was added to the bath at a constant point. Aeration was accomplished by forcing air through a small size glass tube at the rate of about 200 bubbles per minute. The temperature varied between $36^{\circ} \mathrm{C}$. and $38^{\circ} \mathrm{C}$. This change of temperature does not appreciably alter the activity of the segment.

After the segments are placed in their respective baths there is a period of inactivity, the duration of which depends upon the kind of perfusion bath and the amount of chilling to which the segment has been subjected. A segment perfused in Tyrode's or one that has cooled much below body temperature has a longer period of inactivity than a segment bathed in Locke's or a segment whose temperature has not been allowed to fall much below body temperature.

The recorded amplitude of the movements of the segments varies, of course, with length of lever arm, length of segment, etc., but these factors were controlled. The length of time a segment has been in action also affects the amplitude; early it is small and irregular, later it increases and becomes regular and after 3 or 4 hours it slowly decreases. For a given segment the amplitude is greater when perfused in Locke's than when in Tyrode's.

Shortly after the beginning of rhythmical movements the segments bathed in Tyrode's solution rapidly lose the greater part of their tonus while the loss of tonus of segments in Locke's is more gradual and less complete. If one substitutes Locke's for Tyrode's after the segment in Tyrode's has lost its tonus a portion of the lost tonus is regained and if it is now replaced into Tyrode's it will again rapidly lose the regained tonus.

If adrenalin is added when the segment is bathed in Locke's the loss of tonus is greater than when in Tyrode's, indicating that in the former the segment has greater residual tonus. The interval of depression is shorter in Locke's than in Tyrode's. If a segment in Tyrode's has been long inactive from the action of adrenalin it may be activated by substituting Locke's for Tyrode's; this does not happen if fresh Tyrode's is substituted.

A fairly constant $\mathrm{pH}$ was obtained, Locke's, $\mathrm{pH}$ 7.6, Tyrode's, $\mathrm{pH}$ 7.78. During the experiment due to the active aeration the $\mathrm{pH}$ increases to $8.05 \pm$ for Locke's and 8.2 \pm for Tyrode's. The pH was not purposely altered during the experiment by the use of chemicals but when a lower $\mathrm{pH}$ was desired a fresh bath was substituted for the used bath. This procedure shows that a change of $\mathrm{pH}$ within the limits given does not materially alter the activity of the segment.

Although there are individual differences in the segments it has been observed that as a rule those segments immersed in Locke's maintain their activity at a higher level and for a longer period of time than do those in Tyrode's solution.

The difference in effectiveness of these 2 baths was not, in our experiments, due to dextrose or concentration of magnesium chloride. Sollman ${ }^{4}$ has recently suggested that there exists an optimum concentration of buffer substances in perfusion baths and that this concentration varies with the size of bath and its effective aeration.

Under the conditions described a segment of rabbit's or cat's small intestine perfused in Locke's solution has a shorter period of inactivity, less early irregular activity, more gradual and less complete loss of tonus, a greater amplitude of contraction, the ability for more rapid recovery from adrenalin and greater duration of activity than a segment perfused in Tyrode's solution.

4 Sollman, T., von Oettingen, W. F., and Ishikawa, Y., Am. J. Physiol., 1928, $1 \times x \times v, 118$ 